\title{
BMJ Open Importance of clinical educators to research use and suggestions for better efficiency and effectiveness: results of a cross-sectional survey of care aides in Canadian long-term care facilities
}

\author{
T K T Lo, ${ }^{1}$ Matthias Hoben, ${ }^{1}$ Peter G Norton, ${ }^{2}$ Gary F Teare, ${ }^{3}$ Carole A Estabrooks ${ }^{1}$
}

To cite: Lo TKT, Hoben M, Norton PG, et al. Importance of clinical educators to research use and suggestions for better efficiency and effectiveness: results of a cross-sectional survey of care aides in Canadian long-term care facilities. BMJ Open 2018;8:e020074. doi:10.1136/ bmjopen-2017-020074

- Prepublication history and additional material for this paper are available online. To view these files, please visit the journal online (http://dx.doi. org/10.1136/bmjopen-2017020074).

Received 13 October 2017

Revised 1 May 2018

Accepted 6 June 2018
Check for updates

${ }^{1}$ Faculty of Nursing, University of Alberta, Edmonton Clinic Health Academy, Edmonton, Alberta,

Canada

${ }^{2}$ Department of Family Medicine, University of Calgary, Calgary,

Alberta, Canada

${ }^{3}$ Saskatchewan Health

Quality Council, Saskatoon,

Saskatchewan, Canada

Correspondence to

Dr T K T Lo;

thomas.lo@ualberta.ca

\section{ABSTRACT}

Objective This study explored the effect of clinical educators as facilitators of research use and how it may be modified by organisational context in the settings. Design Cross-sectional observational study. Setting A representative sample of 91 residential longterm care (LTC) facilities across Western Canada. Participants We used surveys to collect data from the frontline care aides and information about the organisational context of the care units.

Outcome measure and explanatory variables We assessed research use (the outcome) with the Conceptual Research Utilization (CRU) scale. Explanatory variables in the multiple regression analysis were facilitation, organisational context and the interaction terms. Facilitation was measured by the frequency of contacts between care aides and clinical educator or person who brings new ideas about resident care. Three core organisational context variables were measured using the Alberta Context Tool.

Results We included data of 3873 care aides from 294 care units in the LTC facilities. We found significant associations between CRU and facilitation, leadership, culture and evaluation. Interactions of facilitation $\mathrm{x}$ leadership and facilitation $x$ culture were negative. The coefficient of the facilitation $x$ evaluation term in the regression model was positive $(0.019,95 \% \mathrm{Cl} 0.012$ to 0.026 ), suggesting synergistic effects between facilitation and a well-developed process to evaluate care quality using relevant data.

Conclusions Findings indicate clinical educators are effective facilitators of research use among the care aides, but the effect is modified by organisational context. For greatest impact, managers can direct efforts of the clinical educators to care units where leadership and culture ratings are lowest, but a proficient feedback and evaluation process is in place. This understanding enables managers to deploy clinical educators (a scarce resource in LTC settings) most efficiently.

\section{BACKGROUND}

Concerns about the quality of long-term care (LTC) for older adults have been documented
Strengths and limitations of this study

- This study provides insight into the association between facilitation efforts of the clinical educators and research use in long-term care under different organisational context conditions using two-way interaction terms between facilitation and the organisational context variables in multiple regression analysis.

- Use of vigorously monitored data, clinical microsystem (care unit) measures and a large representative sample contributes positively to the validity of the findings.

- Because of the cross-sectional design of the study, causality cannot be inferred.

in many reports internationally. ${ }^{1-3}$ The issues noted repeatedly are the wide gaps between evidence and practice in LTC settings and the challenges in implementing quality improvement strategies. ${ }^{45}$

One conceptual framework that is commonly applied to understand the success of implementing evidence is the Promoting Action on Research Implementation in Health Services (PARiHS) framework. ${ }^{67}$ In this framework, implementation of evidencebased practice in healthcare is viewed as a function of three elements: evidence, facilitation and context. ${ }^{78}$ Evidence can include research evidence, clinical experience and patient choice. ${ }^{6}$ Facilitation describes the types of support that care providers receive to enable change ${ }^{6}$ and it is achieved when facilitators carry out a specific role to help individuals apply evidence into practice. ${ }^{9}$ Context is the setting in which a change strategy is implemented, where the forces at work are leadership, culture and evaluation (feedback and/or action on relevant data such as quality-of-care indicators). ${ }^{6}$ Thus, 
successful implementation of evidence occurs when evidence is robust, appropriate facilitation is present and organisational context is optimal with strong leadership, supportive culture and appropriate evaluation. ${ }^{9}$

Moreover, original developers of the PARiHS framework stated that the three critical elements of the framework 'have a dynamic, simultaneous relationship' and that the use of evidence in practice results from the 'interplay and interdependence' of these elements. ${ }^{7-9}$ A dynamic relationship means that the elements 'interact or act as modifiers'; for example, the same facilitation activity may have different effects under different context conditions. ${ }^{10}$ Yet, researchers and decision-makers have paid little attention to these interactions and how they may affect use of research evidence in practice. ${ }^{10}$ Opportunities can be missed to make research evidence use more successful. Thoughtful design of implementation strategies requires taking into account these interacting forces between the critical elements.

In LTC settings, up to $80 \%$ of direct care is provided by the care aides who are unregulated, non-professional care providers under the supervision of nurses. ${ }^{11}$ The care aides mostly are women, have a high school diploma and a care aide certification. ${ }^{11}$ Other characteristics of care aides, including job and vocational satisfaction and psychological conditions, have been previously reported. ${ }^{112}$ Nurse educators provide educational and clinical guidance to an array of nursing staff members including the care aides. ${ }^{13}$ They are experienced nurses who typically have baccalaureate preparation in nursing and may have advanced training in areas such as wound management and dementia care. ${ }^{1415}$ Their tasks include monitoring other care providers, facilitating professional development of staff members, promoting evidence-based practices, acting as an information source, and developing policies and procedures based on research findings. ${ }^{16}$ The presence of clinical educators is positively associated with research use in hospitals. ${ }^{17} 18$ However, the influence of the facilitation roles of the clinical nurse educators on research use in LTC has not been well studied. Hence, our objectives in this study were twofold: (1) to explore the effects of clinical educators as facilitators of research evidence use in LTC and (2) to assess the interactions of the elements in the PARiHS framework in this setting. We hypothesised that facilitation and favourable organisational context have synergistic effects on research use because these elements have been individually shown to have positive effects on this outcome. ${ }^{17-19}$

\section{AIMS}

The specific aims of this study were: (1) to examine the association between clinical educators' contact with the care providers and conceptual research use by the frontline care aides in residential LTC settings and (2) to investigate how the effects of facilitation may be modified by the core PARiHS organisational context variables.

\section{METHODS}

\section{Design and data collection}

Translating Research in Elder Care (TREC) is a pan-Canadian research programme with a longitudinal cohort study as its central component. ${ }^{20} 21$ The programme aims to improve the quality of resident care and quality of staff work life, and ultimately residents' quality of life. ${ }^{21}$ The TREC study cohort is a representative, stratified random sample of LTC facilities. Stratification is by health region, owner-operational model (public, private or voluntary not for profit) and size (small $<80$ beds, medium $=80-120$ beds or large $>120$ beds).${ }^{20}$ TREC research uses data that are subject to rigorous monitoring and control. ${ }^{20}$ It employs structured computer-assisted personal interviews and custom-designed software to strengthen data validity and usability. Interviewing protocols and data cleaning processes safeguard data integrity and completeness. These procedures keep missing data to a minimum and, where there are missing data, completely at random. A detailed description of TREC's data quality programme has been published. ${ }^{22}$

In this cross-sectional observational study, we used TREC data collected between September 2014 and May 2015. During this period, survey data were collected from allied health professionals, care aides, care unit managers, clinical specialists and nurses at 91 residential LTC facilities in 3 Canadian provinces (British Columbia, Alberta and Manitoba). We focused on the care aide data. In LTC facilities, the majority of direct care is provided by care aides who are under the supervision of registered nurses, registered psychiatric nurses and/or licensed practical nurses. ${ }^{11}$ Inclusion criteria for care aides were: (1) able to identify a care unit where she/he worked more than $50 \%$ of the time, (2) had worked on that care unit for 3 months or longer and (3) worked at least six shifts per month on that care unit. We focused on care units because they are the clinical microsystems in LTC facilities where care is provided, and quality and safety practices are made. ${ }^{23}$ Moreover, some evidence supports organisational context as a care unit-level construct in the PARiHS framework. ${ }^{23}$

Data collected included information about care aide demographics, research or evidence-based practice use, quality of work life, organisational context and other factors postulated to influence research use among the care aides. Because we aggregated the measures of facilitation and organisational context to the care unit level (further described in the Variables section), only data from care units with eight or more care aide respondents were included in this study. This criterion was guided by aggregation statistics, including interclass correlations, eta-squared and omega-squared indices ${ }^{23}$ and was used to maintain the stability of facilitation and context data at the care unit level. 


\section{VARIABLES}

\section{Outcome variable}

We measured research use with the Conceptual Research Utilization (CRU) scale. ${ }^{24}$ CRU measures a non-instrumental form of research use. It assesses whether research evidence influences the thinking and action of care providers, rather than influences the direct use of, for example, a protocol to prevent injury falls. Five items are scored on a 5-point frequency scaled from 1 (never) to 5 (almost always). The overall CRU score is the mean of the five individual item scores. The CRU scale has been validated and used in studies involving the care aides. ${ }^{19} 24$

\section{Explanatory variables}

Our main explanatory variables were facilitation and organisational context. We measured facilitation with two items: (1) frequency of contacts between care aides and nurse specialists or clinical educators and (2) the presence of a person who brings new ideas to the care unit about resident care. Both items were scored on a 5-point frequency scale from 1 (never) to 5 (almost always). Care aides who never or rarely (scores 1 or 2 ) contact with clinical educators or a person who brings new ideas to the care unit were considered to be not receiving support for research use; those who had occasional, frequent or almost always contact (scores of 3-5) were considered to have received research use support. The proportions of care aides receiving research use support in the care units were calculated and categorised into quartiles to reflect four levels of facilitation (low, moderately low, moderately high and high). This approach is consistent with a previous study that also assessed clinical educators as facilitators of research use. ${ }^{18}$

Data about context were collected using the Alberta Context Tool (ACT). The ACT is designed to specifically assess modifiable elements of organisational context in healthcare settings, and its development was guided by the PARiHS framework. The ACT measures 10 concepts of organisational context: leadership, culture, evaluation, social capital, formal interactions, informal interactions, resources and organisational slack (staffing, space and time). ${ }^{2526}$ The LTC version of ACT used in our care aide survey collects context information of the care units. ${ }^{23}$ In this study, we focused on the three core context variables as defined by the PARiHS framework: leadership, culture and evaluation/feedback. ${ }^{8}$ Each of these three scales is measured with six items, and each item is scored on a 5-point Likert scale. ${ }^{26}$ Data for each item are summed, and the mean is calculated to provide a score ranging from 1 to $5 .^{26}$ Leadership is defined as the actions of formal leaders in an organisation (care unit) to influence change and excellence in practice. Thus, the items in the leadership scale generally reflect emotionally intelligent leadership. ${ }^{26}$ A higher leadership score denotes stronger leadership, and may reflect formal leaders of the care unit more regularly look for feedbacks even they are difficult to hear, focus on success instead of failure, handle stressful situations calmly and/or effectively resolve conflicts. Culture is defined as the way 'we do things' in the work units. The items in this scale generally reflect a supportive work culture. ${ }^{26}$ Higher culture score denotes more supportive culture, and may reflect that care aides in the work unit receive recognitions more often, feel that they are members of a supportive work group and/ or are supported to learn new knowledge to do the job better. Evaluation/feedback is defined as the process of using data to assess group/team performance and to achieve outcomes. ${ }^{26} \mathrm{~A}$ higher score denotes a well-developed process to evaluate care quality using relevant data, and may reflect that the workers in the care unit more routinely receive information about their performance, discuss this information and/or formulate action plans to enhance care quality. A sample item for each of the leadership, culture and evaluation/feedback scales can be found in the online supplementary file. The ACT scales have been validated in LTC settings. ${ }^{27}$ The estimated Cronbach's alpha coefficients were 0.84 (leadership), 0.77 (culture) and 0.80 (evaluation), indicating internal consistency reliability of the three scales. ${ }^{27}$ Acceptability of the scales was also demonstrated, with $93.5 \%$ of the care aides provided complete data. ${ }^{27}$

Because we collected data about care unit context from the care aides (micro-level) but context is a higher level construct, we aggregated this information to the care unit level before categorising the units into quartiles that reflect low, moderately low, moderately high and high organisational context. This is consistent with an earlier study ${ }^{18}$ and with how the facilitation measure was treated, as described in the first paragraph of Explanatory Variables section. The four levels of the quartile-based approach also support a more meaningful interpretation of the estimated effect of the main explanatory variables than a per unit score increase in the ACT leadership, culture or evaluation scale.

\section{Control variables}

Our selection of control variables was guided by the literature $^{19}$ and included characteristics of care aides, care units and LTC facilities. We included variables previously found to have statistically significant associations with CRU in care aides. ${ }^{19}$ Control variables included measures of care aide burn-out, belief suspension and attitude towards research use. ${ }^{20}$ To measure burn-out, we used the short form of the Maslach Burnout Inventory (MBI) general survey, which contains nine items scored on a 7 -point Likert scale. ${ }^{20}$ From these items, the scores for emotional exhaustion, cynicism and job efficacy were derived. Belief suspension is the degree to which a care provider can suspend previous beliefs in order to implement new evidence, and was measured with a three-item scale. ${ }^{20}$ The attitude towards research use score was derived from six items scored on a 5-point Likert scale. ${ }^{20}$ Use of these measures has been demonstrated in other studies. ${ }^{1920}$ The complete list of variables of this study can be found in the online supplementary file. 


\section{Statistical analysis}

We summarised the characteristics of our sample using descriptive statistics, computing the means and SDs for continuous variables and proportions for categorical variables.

Because data for both the outcome measure and our explanatory variables were collected using TREC survey, we examined whether there was any major concern with common-method variance (CMV) before examining associations. We performed Harman's single-factor test to assess the extent of $\mathrm{CMV}^{28}$ which is the amount of spurious correlation between variables created by using the same data collection method (TREC survey). CMV can be a concern when results show that a single factor emerges and accounts for $>50 \%$ of the variance in the data. ${ }^{28}$ We conducted Harman's single-factor test that included all survey items of CRU, facilitation, leadership, culture and evaluation.

To assess the association between CRU and the explanatory variables, we used multiple linear regression analysis. The Wald $\chi^{2}$ test was used to test the full model against the null model. An R-squared statistic was used to estimate the amount of variance explained by the full model.

Data in this study have a hierarchical structure, with care aides nested within care units and care units nested within LTC facilities. To account for potential correlation of care aide data in the care units, and care units in LTC facilities, we used multilevel mixed-effects regression analysis. ${ }^{29}$ The between care units and between facilities variability were modelled as random intercepts at the two (unit and facility) levels. A likelihood-ratio test was run to determine whether the care unit or facility variance was significant, in which case a multilevel model would be preferred over a one-level ordinary linear regression model. Our primary interest was the fixed-effect estimates represented by the regression coefficients. Because we collapsed each of the facilitation, leadership, culture and evaluation variables into four rating levels, the coefficient for these variables in the regression model can be interpreted as the estimated change in the outcome (CRU) per level increase (from low, moderately low, moderately high, to high) in the respective variable.

We included three interaction terms in the regression models. Because facilitation was viewed as the pivotal element, ${ }^{6}$ we considered pairwise interactions between facilitation and the organisational context variables: facilitation $\mathrm{x}$ leadership, facilitation $\mathrm{x}$ culture and facilitation $\mathrm{x}$ evaluation. As an example, the facilitation $\mathrm{x}$ leadership term explored how the effect of facilitation may be modified by different levels of leadership. We illustrated a significant interaction $(p<0.05)$ by plotting the modified effects on a graph. All statistical analyses were performed in Stata V.13.1 (StataCorp LP).

\section{Informed consent}

Written informed consent to participate was received from the study participants before interviews.

\begin{tabular}{|c|c|}
\hline Characteristics & \\
\hline Female (\%) & 89.78 \\
\hline English as a second language (\%) & 38.71 \\
\hline \multicolumn{2}{|l|}{ Age group, years (\%) } \\
\hline$<20$ & 0.08 \\
\hline $20-24$ & 3.51 \\
\hline $25-29$ & 6.64 \\
\hline $30-34$ & 10.35 \\
\hline $35-39$ & 12.55 \\
\hline $40-44$ & 15.21 \\
\hline $45-49$ & 14.82 \\
\hline $50-54$ & 15.67 \\
\hline $55-59$ & 11.57 \\
\hline $60-64$ & 7.23 \\
\hline $65-70$ & 2.19 \\
\hline$>70$ & 0.18 \\
\hline High school completed (\%) & 94.06 \\
\hline \multicolumn{2}{|l|}{ Maslach Burnout Inventory } \\
\hline Emotional exhaustion (SD) & $2.45(1.73)$ \\
\hline Cynicism (SD) & $2.45(1.66)$ \\
\hline Job efficacy (SD) & $5.43(0.80)$ \\
\hline Belief suspension (SD) & $4.08(0.80)$ \\
\hline Attitude towards research (SD) & $4.31(0.47)$ \\
\hline $\begin{array}{l}\text { Research use, Conceptual Research } \\
\text { Utilization (SD) }\end{array}$ & $4.07(0.75)$ \\
\hline
\end{tabular}

\section{Public involvement}

Participants of TREC surveys were the staff members at the residential LTC facilities. Facility staff members were not involved in the development of research questions or specific aims, but they provided inputs and shaped the interviewing process and survey questions. They also provided us inputs for the dissemination of our results. We have developed a process to produce feedback reports that tailor to the facility level and the frontline care providers (care aides).

\section{RESULTS}

\section{Sample characteristics}

Our final dataset included observations from 3873 care aides working in 294 care units from 91 LTC facilities. The number of missing data in the variables of interest (CRU, facilitation, leadership, culture or evaluation) did not exceed $1 \%$. Almost $90 \%$ of the care aides were female, and $40 \%$ had English as a second language. Just over $30 \%$ were 40-49 years old (the most common age group). Detailed characteristics of the care aides in our sample are shown in table 1. Characteristics of the care units and 
LTC facilities can be found in the online supplementary file.

\section{Regression model statistics}

Harman's single-factor test result $(29.9 \%)$ was well below the threshold, indicating that no factor accounted for the majority of the variance in the data and suggesting that CMV was not a serious issue in this study. Our multivariable regression analysis included 3725 observations (96.2\%). Wald $\chi^{2}$ test result rejected the null hypothesis where all coefficients of the independent variables in the regression model were zero $(p<0.0001)$, indicating that our model was statistically significant. The R-squared statistic was 0.27 , indicating that about $27 \%$ of the variance in the outcome (CRU) were explained by our model. A likelihood-ratio test to compare the results of our multilevel model with a standard (one-level) ordinary linear regression model favoured the multilevel model $(\mathrm{p}=0.0017)$.

Association between research use and facilitation and context The main regression analysis results (fixed effects) are shown in table 2. All independent variables in our model were statistically significantly associated with CRU except age, MBI exhaustion and MBI cynicism.

As indicated by the coefficients in our regression model, the associations between CRU and facilitation, leadership, culture or evaluation were positive: greater research use was associated with higher facilitation and organisational context. Coefficients of the interaction terms indicate a negative interaction effect between facilitation and leadership (-0.014) and a negative interaction between facilitation and culture $(-0.030)$, but a positive interaction between facilitation and evaluation (0.019). These results indicate that the effect of facilitation on CRU depended on the rating levels of the three organisational context variables. For example, when leadership level in care units was low (leadership=1) and other variables remain constant, each increase in level of facilitation was associated with an increase in CRU score of 0.047 (facilitation $+($ leadership $\mathrm{x}$ facilitation $)=0.061(1)-0.014(1 \times 1))$. But in care units where leadership was high $(=4)$, each increase in the level of facilitation led only to an increase in CRU score of $0.007(0.061(1)-0.014(1 \times 4))$. Diminishing effects of facilitation on CRU in care units from low leadership rating to high is illustrated in figure 1A. Note that the slopes of the regression lines decrease with each increase in leadership rating.

Similarly, the effect of facilitation on CRU was modified by the culture variable, with a negative interaction between facilitation and culture. Although each increase in the level of facilitation was associated with a change in CRU, the effect diminished as culture ratings in the care units varied from low to moderately high. Ultimately, in care units with high culture, the slope of the regression line became negative, indicating a decrease in CRU for increasing levels of facilitation (figure 1B).

The pattern in figure 1C contrasts with those in the other two figures (figure 1A,B). Here, the slopes increase
Table 2 Factors associated with the conceptual use of research by care aides: results of multilevel mixed-effects regression analysis

\begin{tabular}{|c|c|c|}
\hline $\begin{array}{l}\text { Independent } \\
\text { variable }\end{array}$ & $\begin{array}{l}\text { Coefficient } \\
\text { (fixed effects) }\end{array}$ & $\mathrm{P}(95 \% \mathrm{Cl})$ \\
\hline Facilitation & 0.061 & 0.003 (0.021 to 0.101$)$ \\
\hline Leadership & 0.035 & 0.006 (0.010 to 0.059$)$ \\
\hline Culture & 0.056 & $<0.001$ (0.032 to 0.081$)$ \\
\hline Evaluation & 0.040 & 0.010 (0.010 to 0.071$)$ \\
\hline $\begin{array}{l}\text { Facilitation x } \\
\text { leadership }\end{array}$ & -0.014 & $<0.001(-0.020$ to -0.007$)$ \\
\hline Facilitation $\mathrm{x}$ culture & -0.030 & $<0.001(-0.037$ to -0.023$)$ \\
\hline $\begin{array}{l}\text { Facilitation } \mathrm{x} \\
\text { evaluation }\end{array}$ & 0.019 & $<0.001$ (0.012 to 0.026$)$ \\
\hline Female & 0.059 & 0.003 (0.020 to 0.098$)$ \\
\hline $\begin{array}{l}\text { English as a second } \\
\text { language }\end{array}$ & -0.282 & $<0.001(-0.324$ to -0.240$)$ \\
\hline Age & -0.002 & $0.125(-0.004$ to 0.001$)$ \\
\hline $\begin{array}{l}\text { High school } \\
\text { completed }\end{array}$ & 0.036 & 0.001 (0.015 to 0.056$)$ \\
\hline $\begin{array}{l}\text { MBI emotional } \\
\text { exhaustion }\end{array}$ & -0.036 & $0.077(-0.077$ to 0.004$)$ \\
\hline MBI cynicism & 0.007 & 0.797 ( -0.048 to 0.063$)$ \\
\hline MBI job efficacy & 0.102 & $<0.001$ (0.075 to 0.129$)$ \\
\hline Belief suspension & 0.236 & $<0.001(0.212$ to 0.261$)$ \\
\hline $\begin{array}{l}\text { Attitude towards } \\
\text { research }\end{array}$ & 0.259 & $<0.001$ (0.224 to 0.294$)$ \\
\hline \multicolumn{3}{|l|}{ Unit type } \\
\hline \multicolumn{3}{|l|}{$\begin{array}{l}\text { General LTC } \\
\text { (reference) }\end{array}$} \\
\hline Secure dementia & -0.011 & $0.231(-0.030$ to 0.007$)$ \\
\hline $\begin{array}{l}\text { Secure mental } \\
\text { health/psychiatric }\end{array}$ & -0.066 & $0.589(-0.308$ to 0.175$)$ \\
\hline $\begin{array}{l}\text { Non-secure } \\
\text { dementia }\end{array}$ & -0.104 & $0.001(-0.058$ to 0.075$)$ \\
\hline Other & 0.008 & $0.805(-0.167$ to -0.041$)$ \\
\hline No of beds & 0.0002 & $<0.001(0.0002$ to 0.0003$)$ \\
\hline \multicolumn{3}{|l|}{ Operation model } \\
\hline \multicolumn{3}{|l|}{ Public (reference) } \\
\hline Private & 0.064 & $<0.001$ (0.043 to 0.085$)$ \\
\hline $\begin{array}{l}\text { Voluntary non- } \\
\text { profit }\end{array}$ & -0.013 & $0.002(-0.021$ to -0.005$)$ \\
\hline Constant & 1.318 & $<0.001(1.113$ to 1.524$)$ \\
\hline
\end{tabular}

LTC, long-term care; MBI, Maslach Burnout Inventory.

from the care units with low evaluation ratings to those with higher evaluation ratings. This figure illustrates the positive interaction between facilitation and evaluation/ feedback, in contrast to the negative interactions with the other context variables of leadership and culture. Higher levels of facilitation were positively associated with CRU, and the effect was progressively greater with higher evaluation ratings in the care units. This pattern illustrates 

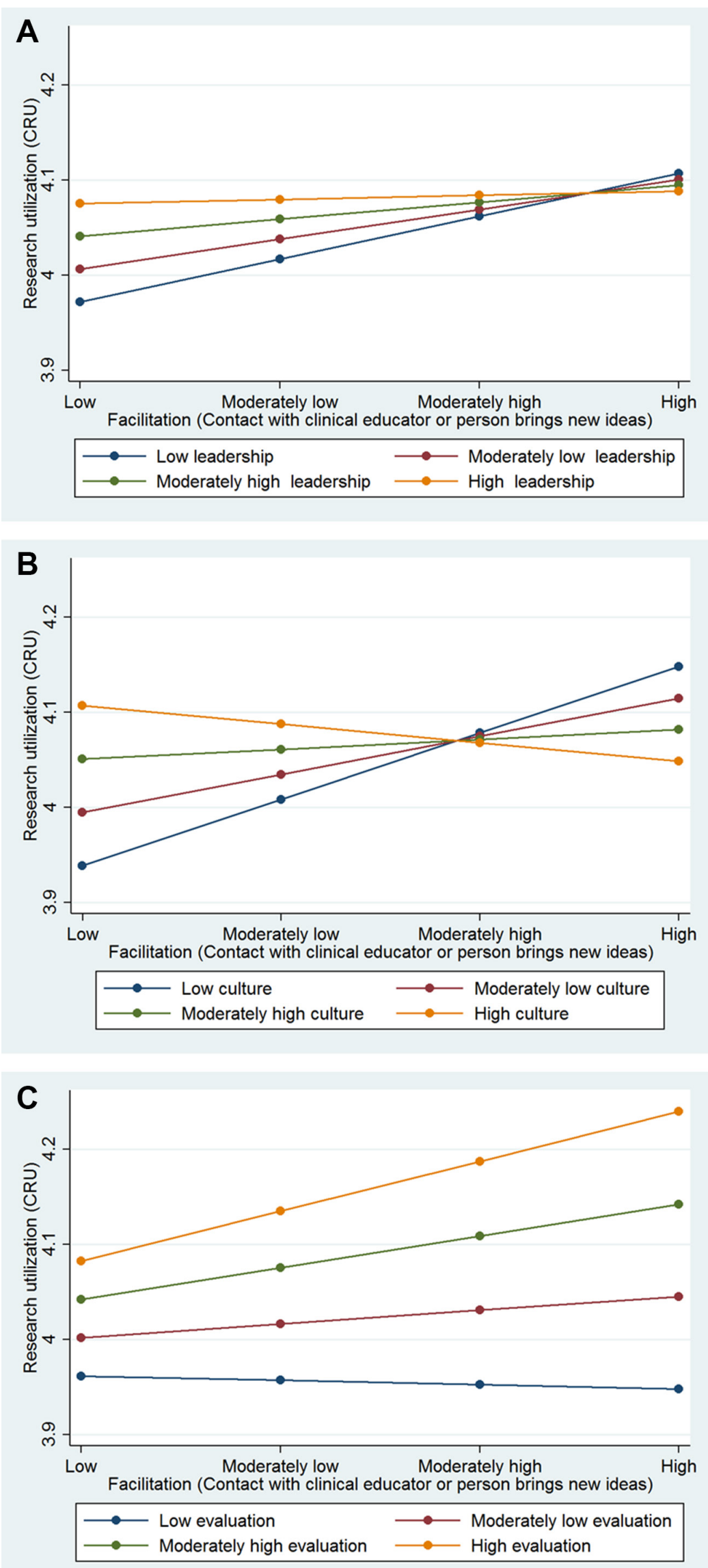

Figure 1 Effect of interaction between: (A) facilitation and leadership, (B) facilitation and culture and (C) facilitation and evaluation on research use in the care aides at long-term care facilities. CRU, Conceptual Research Utilization. 
the synergistic effects of facilitation and evaluation on conceptual research use.

\section{DISCUSSION}

This study is an important first step in discerning the interactions between the critical elements in the PARiHS framework. A better understanding of these interacting elements can lead to more effective designs of implementation strategies to narrow evidence-practice gaps and improve quality in LTC. Our results indicate that clinical educators are effective facilitators of research use among care aides and that each of the three core organisational context variables (leadership, culture, evaluation) is positively associated with the conceptual use of research. Our results also demonstrate the significant interactions between facilitation and organisational context by illustrating that the effectiveness of facilitation depends on leadership, culture and evaluation. Nonetheless, the interactions between facilitation and favourable organisational context are complex and not always positive.

The coefficient of the term for facilitation $x$ leadership in our regression model demonstrates how the effect of facilitation was modified in care units with different levels of leadership. It indicates a diminishing effect of facilitation on research use as leadership rating increased. Previously, Kitson et al proposed that low-context conditions can be overcome by high facilitation. ${ }^{6}$ Our results suggest that this perception may be a partial view of the interaction between these elements. We observed that facilitation appears to compensate for low organisational context, and the effect of facilitation was strongest where leadership was low, but the effect became weakest where leadership was high. Thus, the effect of facilitation was not fixed and depended on organisational context. There may be two possible explanations. First, the amount of new idea and actual support for research use offered by clinical educators might have been influenced by the leadership in the care units. The clinical educators became less efficient or less focused in promoting research use when leadership rating on the care units was high. This explanation conforms to the idea that clinical educators use a wide range of approaches (advice, education, feedback, support, team building) and operate differently depending on organisational need. ${ }^{9}$ Second, in care units where good leaders supported and motivated care aides and research use was already high, there was little room to change when the clinical educators were carrying out similar tasks as the frontline leaders. This would occur even when the clinical educators were as focused as those in care units with lower ratings of leadership. Hence, there may be a ceiling effect to how much clinical educators can add to research use when leadership is already strong. However, the true mechanisms behind our observations are unclear. Further research can clarify the mechanisms, using methods such as qualitative interviews with the clinical educators, the care aides and the leaders working under different levels of facilitation and leadership.
We also observed diminishing returns of facilitation on research use in care units with higher ratings for culture. Facilitation had the biggest effect on research use in care units with the lowest culture scores. In care units with the highest culture scores, the overall effect of facilitation was negative. These results may reveal an antagonistic action of facilitation and culture, with forces of high-intensity facilitation and strong culture potentially working against each other to produce negative effects. Increasing research use often requires care providers to make changes, but such changes may not necessarily align with current organisational objectives, expectations or beliefs. Activities of clinical educators might have clashed with a strong culture, leading to suboptimal working relationships and dysfunction. ${ }^{30}$ Additionally, changes might have disturbed a state of equilibrium that was more obvious in care units with higher culture scores. For example, one item in the culture measurement tool asked care aides how much they agreed with the statement: 'My organisation effectively balances best practice and productivity.' In care units where care aides perceived that use of evidencebased practice and productivity were already in good balance, stimuli to change might have negatively affected research use, productivity or both. We suggest that future studies more thoroughly investigate how the interaction between facilitation and culture affects research use.

Finally, we observed synergistic effects of facilitation and evaluation (a proficient system of feeding back data and evaluation of care quality) on research use. Kitson $e t$ al suggested that the effects of PARiHS elements are not additive. ${ }^{6}$ Our results show that the combined effect of frequent contact of clinical educators with the care aides and a proficient evaluation system was more pronounced than the simple sum of the two effects. Nonetheless, we found some interactions were negative (facilitation $\mathrm{x}$ leadership and facilitation $\mathrm{x}$ culture) while another was positive (facilitation $\mathrm{x}$ evaluation). We rejected our hypothesis because these findings collectively indicate that the interactions between the critical elements of PARiHS are complex and not always synergistic.

\section{IMPLICATIONS}

Our findings have practical implications for narrowing the evidence-practice gap in LTC. First, our results indicate that clinical educators are effective facilitators of research use among care aides. Managers can use clinical educators in targeted approaches to promote evidencebased practices for improving care quality and resident outcomes. Second, our study sheds light on the interactions between facilitation and the core organisational context variables of leadership, culture and evaluation, and consequently on future designs of strategies for change. Findings indicate that clinical educators have the greatest impact on research use in care units with low 
ratings for leadership and culture. Accordingly, managers can direct efforts of clinical educators particularly to care units with these characteristics to gain the best return. Managers can also improve feedback of relevant information, such as quality indicator data, to the care providers to take advantage of the synergistic effects of facilitation and evaluation. This understanding enables managers to deploy clinical educators, a scarce resource in LTC settings, more productively and efficiently.

\section{Strengths and limitations}

Major strengths of our study include the use of rigorously monitored data and a large representative sample of LTC facilities from Western Canada. Our measures aggregated at the care unit level were also methodologically sound because care units are the clinical microsystems in LTC settings, ${ }^{23}$ organisation context can be viewed as a care unit construct in the PARiHS framework, ${ }^{23}$ and interactions between facilitation and organisation context were anticipated. ${ }^{10}$ Our multiple regression analysis also included all variables previously found to be statistically significantly associated with research use by the care aides. These factors contribute positively to both internal and external validity of the results. This study also has limitations. First, our study was cross-sectional and cannot establish causal relationships. Future studies could employ a longitudinal study design to allow causal conclusions to be drawn. Second, we considered facilitation rather homogeneously across care units and facilities, differentiating only the frequency of contacts between clinical educators and care aides. Harvey et al suggested that facilitators operate in different ways and use different skills and attributes. ${ }^{9}$ Future studies could extend our analysis by measuring both quantity and quality of facilitation, including the facilitator skill sets, specialised education, access to research evidence and other information, social networks, and specific facilitation activities. Third, we considered only pairwise interactions and interpreted our results as if the three core organisational context variables (leadership, culture and evaluation) operate in isolation. McCormack et al proposed that these context variables coalesce to enable research implementation. ${ }^{30}$ For example, leadership and culture may be interdependent in shaping a context that is ready for change. ${ }^{8}$ Future studies could explore higher order interactions such as facilitation $\mathrm{x}$ leadership $\mathrm{x}$ culture.

\section{CONCLUSION}

Our study investigated factors that influence research use in LTC settings and examined the interactions between facilitation and the core organisational context variables of leadership, culture and evaluation. Results show that frequent contact of clinical educators with care aides is positively associated with research use among the care aides. Interactions between facilitation and the context variables were significant but not always positive. Clinical educators had the most impact on research use in care units with low ratings for leadership and culture but where a proficient evaluation/feedback process was in place. These findings imply that managers can gain the best return on facilitation activities by directing efforts of the clinical educators to care units with weaker leadership and less supportive culture. Managers can also enhance evaluation/feedback processes to benefit from the synergistic effects on research use. The interactions between critical elements of the PARiHS framework can be leveraged for more effective strategies to narrow the evidence-practice gap.

Acknowledgements The authors are grateful to the participating residential LTC facilities and to the staff members who provided the survey data. The authors acknowledge the Translating Research in Elder Care (TREC) 2.0 research team for its contributions to this study. They also thank Cathy McPhalen of thINK Editing for providing editorial support in accordance with Good Publication Practice (GPP3) guidelines.

Contributors TKTL, PGN and GFT conceptualised and designed the study. PGN and CAE played major roles in the acquisition of data. TKTL undertook the analyses and drafted the manuscript. TKTL, MH, PGN, GFT and CAE contributed to interpretation of the results, provided commentary and critically revised the manuscript for intellectual content and approved the final version.

Funding Funding was provided by the Canadian Institutes of Health Research (ClHR) and partners in the Ministries of Health in British Columbia, Alberta and Manitoba, as well as, regional health authorities in participating $B C$ and $A B$ regions.

Competing interests None declared.

Patient consent Not required.

Ethics approval Ethics approvals were obtained from the research ethics boards of the University of Alberta (PR000037937), the University of British Columbia (H14-00942) and the University of Manitoba (HS17655; H2014:164). Operational approvals were obtained from all relevant healthcare organisations.

Provenance and peer review Not commissioned; externally peer reviewed.

Data sharing statement The data supporting the conclusions of this manuscript are housed in the secure and confidential Health Research Data Repository (HRDR) in the faculty of nursing at the University of Alberta, in accordance with the health privacy legislation of participating TREC jurisdictions. Data specific to this manuscript can be requested through the TREC data management committee ( joseph.akinlawon@ualberta.ca) on the condition that researchers meet and comply with the TREC and HRDR data confidentiality policies.

Open access This is an open access article distributed in accordance with the Creative Commons Attribution Non Commercial (CC BY-NC 4.0) license, which permits others to distribute, remix, adapt, build upon this work non-commercially, and license their derivative works on different terms, provided the original work is properly cited and the use is non-commercial. See: http://creativecommons.org/ licenses/by-nc/4.0/

(c) Article author(s) (or their employer(s) unless otherwise stated in the text of the article) 2018. All rights reserved. No commercial use is permitted unless otherwise expressly granted.

\section{REFERENCES}

1. Rust TB, Wagner LM, Hoffman C, et al. Broadening the patient safety agenda to include safety in long-term care. Healthc Q 2008;11(3 Spec No.):31-4.

2. Cohen CC, Pogorzelska-Maziarz M, Herzig CT, et al. Infection prevention and control in nursing homes: a qualitative study of decision-making regarding isolation-based practices. BMJ Qual Saf 2015;24:630-6.

3. Buljac-Samardzic M, van Wijngaarden JD, Dekker-van Doorn CM. Safety culture in long-term care: a cross-sectional analysis of the Safety Attitudes Questionnaire in nursing and residential homes in the Netherlands. BMJ Qual Saf 2016;25:bmjqs-2014-003397.

4. Abrahamson K, Miech E, Davila HW, et al. Pay-for-performance policy and data-driven decision making within nursing homes: a qualitative study. BMJ Qual Saf 2015;24:311-7. 
5. Rahman AN, Applebaum RA, Schnelle JF, et al. Translating research into practice in nursing homes: can we close the gap? Gerontologist 2012;52:597-606.

6. Kitson A, Harvey G, McCormack B. Enabling the implementation of evidence based practice: a conceptual framework. Qual Health Care 1998;7:149-58

7. Rycroft-Malone J, Harvey G, Seers K, et al. An exploration of the factors that influence the implementation of evidence into practice. $J$ Clin Nurs 2004;13:913-24.

8. Rycroft-Malone J. The PARIHS framework--a framework for guiding the implementation of evidence-based practice. J Nurs Care Qual 2004;19:297-304.

9. Harvey G, Loftus-Hills A, Rycroft-Malone J, et al. Getting evidence into practice: the role and function of facilitation. J Adv Nurs 2002;37:577-88.

10. Helfrich CD, Damschroder LJ, Hagedorn $\mathrm{HJ}$, et al. A critical synthesis of literature on the promoting action on research implementation in health services (PARIHS) framework. Implement Sci 2010;5:82.

11. Estabrooks CA, Squires JE, Carleton HL, et al. Who is looking after Mom and Dad? Unregulated workers in Canadian long-term care homes. Can J Aging 2015;34:47-59.

12. Chamberlain SA, Gruneir $A$, Hoben M, et al. Influence of organizational context on nursing home staff burnout: A crosssectional survey of care aides in Western Canada. Int J Nurs Stud 2017;71:60-9.

13. Graham Gibson C. Nurse educator roles and long-term care. J Nurses Staff Dev 2011;27:259-61.

14. Wall S. Living with grey: role understandings between clinical nurse educators and advanced practice nurses, 2006.

15. Association of Registered Nurses of Newfoundland and Labrador. Registered nurse roles in long term care. St John's, NL, 2013.

16. Milner FM, Estabrooks CA, Humphrey C. Clinical nurse educators as agents for change: increasing research utilization. Int J Nurs Stud 2005;42:899-914.

17. Cummings GG, Estabrooks CA, Midodzi WK, et al. Influence of organizational characteristics and context on research utilization. Nurs Res 2007:56:S24-S39.

18. Estabrooks CA, Midodzi WK, Cummings GG, et al. Predicting research use in nursing organizations: a multilevel analysis. Nurs Res 2007;56:S7-S23.
19. Estabrooks CA, Squires JE, Hayduk L, et al. The influence of organizational context on best practice use by care aides in residential long-term care settings. J Am Med Dir Assoc 2015;16:537.e1-10.

20. Estabrooks CA, Squires JE, Cummings GG, et al. Study protocol for the translating research in elder care (TREC): building context - an organizational monitoring program in long-term care project (project one). Implementation Science 2009;4:1-13.

21. Estabrooks CA, Hutchinson AM, Squires JE, et al. Translating research in elder care: an introduction to a study protocol series. Implement Sci 2009;4:51.

22. Squires JE, Hutchinson AM, Bostrom AM, et al. A data quality control program for computer-assisted personal interviews. Nurs Res Pract 2012;2012:1-8

23. Estabrooks CA, Morgan DG, Squires JE, et al. The care unit in nursing home research: evidence in support of a definition. BMC Med Res Methodol 2011;11:46.

24. Squires JE, Estabrooks CA, Newburn-Cook CV, et al. Validation of the conceptual research utilization scale: an application of the standards for educational and psychological testing in healthcare. BMC Health Serv Res 2011;11:107.

25. Estabrooks CA, Squires JE, Cummings GG, et al. Development and assessment of the Alberta Context Tool. BMC Health Serv Res 2009;9:234

26. Squires J, Hutchinson A, Hayduk L, et al. Alberta Context Tool: User Manual Knowledge Utilization Studies Program. University of Alberta: Knowledge Utilization Studies Program, Faculty of Nursing, University of Alberta: Edmonton, Canada, 2014.

27. Estabrooks CA, Squires JE, Hayduk LA, et al. Advancing the argument for validity of the Alberta Context Tool with healthcare aides in residential long-term care. BMC Med Res Methodol 2011:11:107.

28. Podsakoff PM, MacKenzie SB, Lee JY, et al. Common method biases in behavioral research: a critical review of the literature and recommended remedies. J Appl Psychol 2003;88:879-903.

29. Adewale AJ, Hayduk L, Estabrooks CA, et al. Understanding hierarchical linear models: applications in nursing research. Nurs Res 2007;56:S40-46.

30. McCormack B, Kitson A, Harvey G, et al. Getting evidence into practice: the meaning of 'context'. J Adv Nurs 2002;38:94-104. 